\title{
SINKHOLE SUSCEPTIBILITY ANALYSIS FOR KARAPINAR/KONYA VIA MULTI CRITERIA DECISION
}

\author{
F.Sar1 ${ }^{\text {a }}$ \\ ${ }^{\text {a } S U, ~ C u m r a ~ S c h o o l ~ o f ~ A p p l i e d ~ S c i e n c e s, ~ K o n y a, ~ T u r k e y ~-~ f a t i h s a r i @ ~ s e l c u k . e d u . t r ~}$
}

KEY WORDS: Multi Decision Criteria, Geographical Information Systems, Sinkholes, Sinkhole Susceptibility

\begin{abstract}
:
Sinkholes are being a natural hazard which threads economic and human life. Sudden occurrence characteristic of sinkholes make it unable to escape. There are a lot of factor that activate sinkholes such as geology, irrigation, land use and human related factors. In Karapınar, Konya, there are over 200 sinkholes and this count is getting increased in recent years. Especially active agricultural lands, decreasing ground water level, extreme irrigation by 55267 water wells increase the risk factor of Karapinar. Nowadays, considering the economic contribution of Karapınar to Turkey economy in the field of agriculture, solar energy fields and thermal reactor which will be planned in next few years, prediction of sinkholes and searching for preventation ways are being more important issue.

In this study, sinkhole susceptibility map via AHP was carried out for Karapınar in Konya. Slope, land use, elevation, geology, water wells, distance to roads and settlements criteria are included to determine susceptibility. The weights are calculated with AHP for each criterion and generated susceptibility map is overlapped with existing sinkholes. Suggestions and results are shared for this study.
\end{abstract}

\section{INTRODUCTION}

Considering existing sinkholes, the formations are usually occurred as collapse or subsidence. Especially, limestone with karstic properties is interacting with groundwater and caves are become underground by this dissolution. This structure is then getting weaker and tends to be collapse by a vibration, movement or a natural hazard effect.

Sinkholes are closed depressions in the Earth's surface with internal drainage caused by subsurface dissolution of soluble bedrock in karst landscapes (Miao et al., 2013). Sinkhole formations and ground subsidence phenomenon may cause severe damage to human properties and life (Shaban and Darwich, 2011; Rahimi and Alexander, 2013; Galve et al., 2015; Taheri et al., 2015). Thus, the main objective is generating reliable predictions with susceptibility and hazard maps in sinkhole hazard assessments concept (Waltham et al., 2005; Gutiérrez et al., 2008). Susceptibility maps express the relative probability of a sinkhole occurring or not in the future at any specific place. The generation of susceptibility and hazard maps is primarily based on the analysis of the spatial or the spatiotemporal distribution of sinkhole events occurred in the recent past, respectively. At this point, susceptibility maps should be generated by considering all criteria that increase the risk factor.

Multi Decision Criteria Analysis (MCDA) is a way to identify the best solution between complex criteria via user defined comparison. One of the most applied MCDA approaches is the Analytical Hierarchy Process (AHP) which calculates the weights of criteria among the factors that affect the total suitability (Saaty, 1977, 1980, 1994, 2001; Saaty and Vargas, 1991). AHP refers to the applications which are used to determine the most suitable solutions to the real problems by providing a selection of different data clusters (Arentze and Timmermans, 2000) and calculates the weights associated with criteria via pairwise preference matrix where all criteria are compared against each other (Chen et al., 2010). The calculated weights represent the importance of criteria relatively which will contribute to the generation of suitability map.

In this study, the weights are calculated for each criterion that will be used to generate sinkhole susceptibility map for Karapınar in Konya. The AHP method is used to calculate weights and ArcGIS software is used to generate susceptibility map.

\section{MATERIAL METHOD}

\subsection{Study Area}

The study area is located between Konya city centre, Karaman and Aksaray cities (Figure 1). The main center of the sinkholes are Karapınar district. Karapınar has a volcanic texture and formation addition to desert lands. On the other hand, Karapınar is one of the main agricultural center of Konya with sunflower, sugar beet, wheat and corn. In study area, various rock formations in carbonate forms are located in large area and these rocks have melting characteristics. Thus, in recent years, the sinkhole count is increased and become a natural risk factor for human life and agricultural economy. 


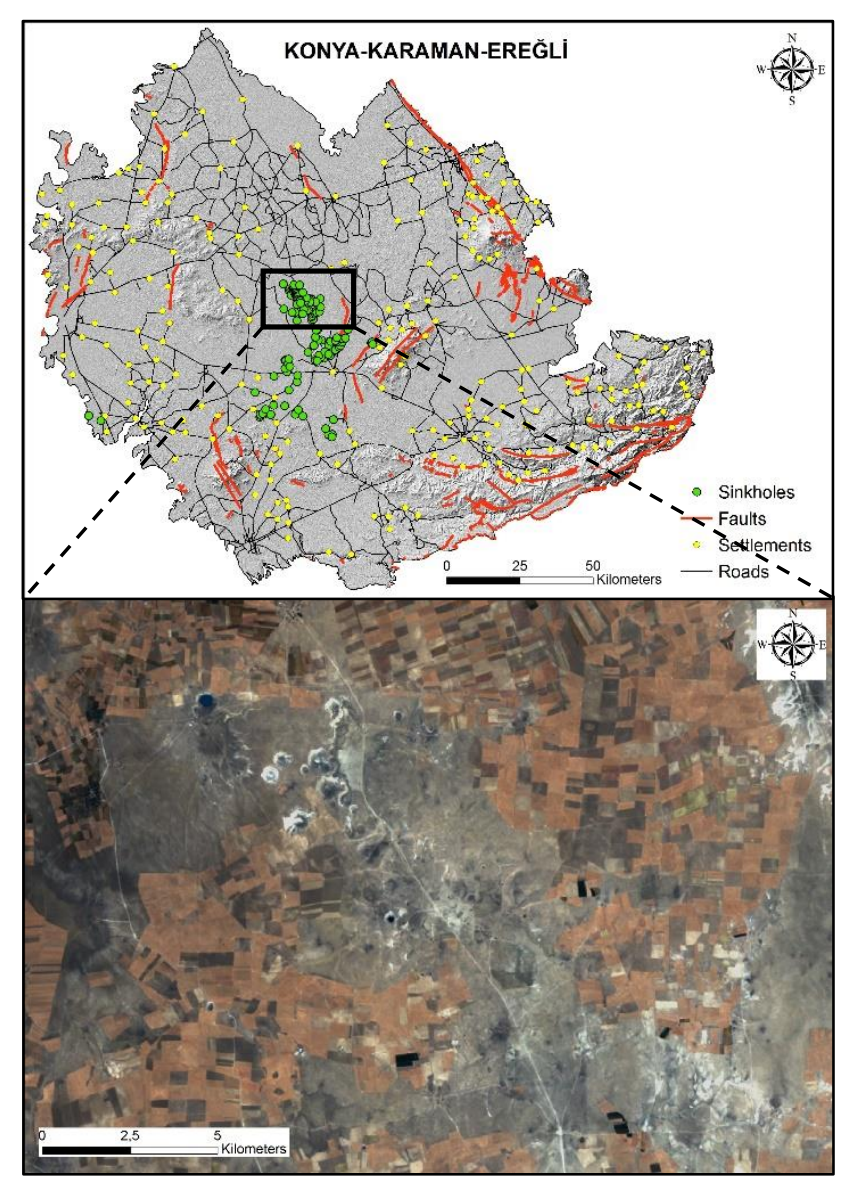

Figure 1. Study Area

\subsection{Criteria Selection}

The criteria selection reflects the requirements and restrictions of sinkhole structures. Sinkhole formation has some assumptions and requirements in the field of topographical, environmental and geological perspective. Each criterion has an activate effect on sinkhole formations and should be analysed together. The criteria which used to generate sinkhole susceptibility map are explained below.

Elevation: While elevation criterion is not a factor directly, elevation is defining geologic and topographic features of the study area. Considering existing sinkholes, they tend to be in low level of plains between 950 and 1020 .

Faults: Faults have effect on geologic features and movements. Usually, earthquakes and active fault lines increase the risk factor of sinkhole formations. Thus, near distances to fault lines are accepted as high rate of susceptible.

Geology: Geology is most important and effective criterion in sinkholes formation. Because sinkholes are a geologic formation, the higher weights must be given to geology criterion. The study area has different geologic formations. Mountains, plains, swamps and volcanic texture can be found in this large area. Considering existing sinkholes, they tend to be located on limestone texture. Due to the weak structure and water resistance, limestone texture tends to collapse or deformation. Existing sinkholes have never been in rocky areas such as pyroclastic and carbonate rocks. Thus, the higher weights are given to limestone.
Land use: Sinkholes are tend to be located in agricultural lands. This can be evaluated with high amount irrigation and use of groundwater mostly. Urban areas also increase the sinkhole susceptibility due to the high pressure on earth with buildings, industrial areas and movements.

Distance to Roads: Considering existing sinkholes, it is possible to say that formations are susceptible to movements. A large amount of sinkhole formations are occurred after harvester or tractor movement. Thus, roads and traffic flow increase the risk factor.

Slope: Similar to elevation, slope criterion has a close relationship with geology due to rapidly changing topography, and geologic formations. Sinkholes are tend to be located in plain lands.

Distance to Settlements: Similar to land use and distance to roads criteria, settlements can also increase the risk factor due to the movement and high pressure to land.

Sinkhole: Considering approximately 200 sinkholes, they tend to be clustered in small area. It is possible to say that new sinkholes will be located very near to others. Thus, another important criterion is distance to existing sinkholes.

Water wells: Water wells are related to irrigation density and groundwater level decreasing. Because the study area has high density of agricultural activities, 55267 water wells have been located in study area. In other words, there is a huge amount of water usage for irrigation and most of this usage is supplied from ground water resources which are given in Figure 2.

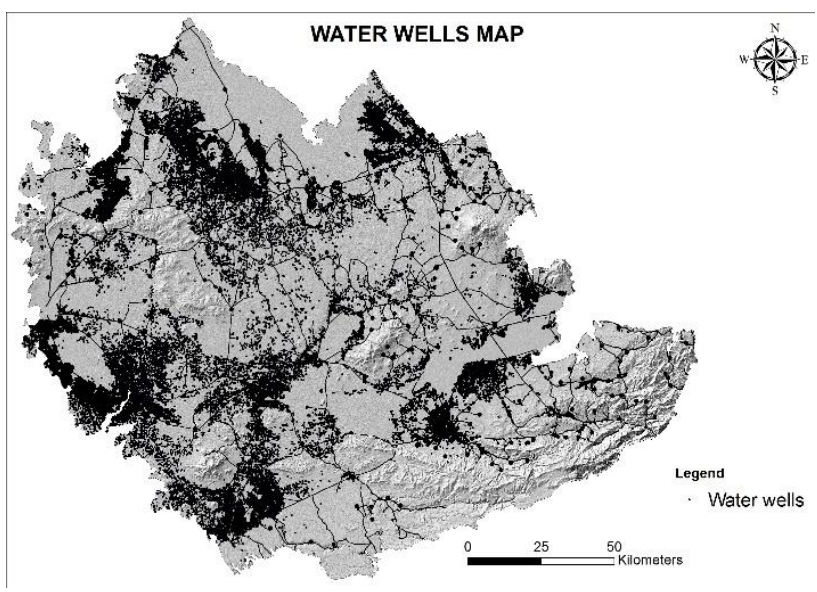

Figure 2. Water wells in study area

\subsection{Analytical Hierarchy Process (AHP)}

The procedure outlined by Saaty $(1977,1980)$ scales the importance of each criterion, from 1 to 9 relatively (Table 1 ). The pairwise matrix includes the scales and determines the importance of criteria (Table 2).

Table 1 . Saaty 1 to 9 Scale

\begin{tabular}{ccccc}
\hline $\mathbf{1}$ & $\mathbf{3}$ & $\mathbf{5}$ & $\mathbf{7}$ & $\mathbf{9}$ \\
\hline Equal & Moderately & Strongly & Very & Extremely \\
\hline
\end{tabular}


Table 2. Pairwise comparison matrix

\begin{tabular}{cccccc}
\hline $\boldsymbol{A}$ & $\boldsymbol{C 1}$ & $\boldsymbol{C 2}$ & $\boldsymbol{C 3}$ & $\ldots$ & $\boldsymbol{C n}$ \\
\hline $\boldsymbol{C 1}$ & $a_{11}$ & $a_{12}$ & $a_{13}$ & $\ldots$ & $a_{1 n}$ \\
$\boldsymbol{C 2}$ & $a_{21}$ & $a_{22}$ & $a_{23}$ & $\ldots$ & $a_{2 n}$ \\
$\ldots$ & $\ldots$ & $\ldots$ & $\ldots$ & $\ldots$ & $\ldots$ \\
$\boldsymbol{C n}$ & $a_{n 1}$ & $a_{n 2}$ & $a_{n 3}$ & $\ldots$ & $a_{n n}$ \\
\hline
\end{tabular}

The pairwise comparison square matrix is defined for maincriteria and sub-criteria to determine the weights. The diagonal element of the comparison matrix is 1 . Each element of the comparison matrix is divided by the sum of its own column sum to generate a normalized matrix with Formula 1.

$a_{i j}^{1}=\frac{a_{i j}}{\sum_{i=1}^{n} a_{i j}}$

Each column of the normalized matrix sum is equal to 1 . Then, each row sum of the normalized matrix is divided by the matrix order. The average of the sum represents the weights of each criterion in pairwise comparison matrix (Formula 2).

$w_{i}=\left(\frac{1}{n}\right) \sum_{i=1}^{n} a_{i j}^{\prime},(i, j=1,2,3, \ldots, n)$

The consistency of the pairwise comparison matrix must be calculated to decide the criteria, comparisons are consistent or not. Therefore, the eigenvalues and eigenvectors of the square pairwise comparison matrix, revealing important details about patterns in the data matrix are calculated (Saaty\& Vargas 1991).Consistency Index (CI) is one of the methods to define the consistency coefficient of the pairwise comparison matrix. $\mathrm{CI}$ is calculated with Formula 3 (Saaty, 1994).

$C I=\frac{\lambda_{\max }-n}{n-1}$

Calculating consistency index depends on the $\lambda \max$ (eigen value) value with Formula 4 (Saaty, 1994).

$\lambda_{\max }=\frac{1}{n} \sum_{i=1}^{n}\left[\frac{\sum_{j=1}^{n} a_{i j} w_{j}}{w_{i}}\right]$

In addition to this, the Random Index (RI) value must be calculated to determine the consistency index. After calculating the CI and RI, consistency ratio (CR) can be calculated with Formula 5. If CR exceeds 0.1, based on expert knowledge and experience, Saaty \& Vargas (1991) recommends a revision of the pairwise comparison matrix with different values (Saaty, 1980).

$C R=\frac{C I}{R I}$

\section{APPLICATION}

Each criterion is mapped and then reclassified with the ArcGIS software according to the defined classes which are illustrated in Figure 3. The layers and the classes are associated with the weights to generate the sinkhole susceptibility map. In each figure, the suitability value is illustrated from highly suitable (green) to none suitable (red) relatively.

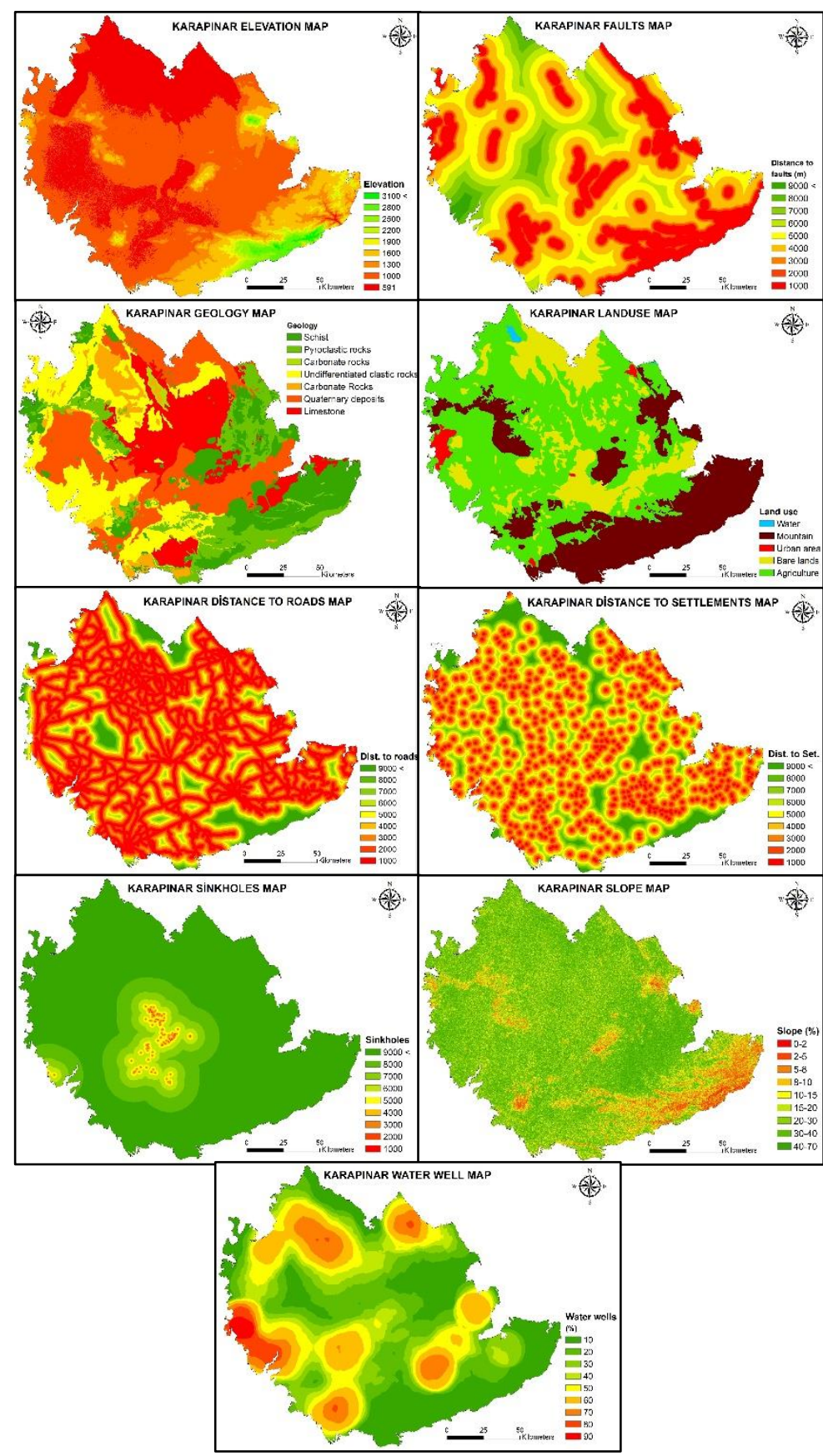

Figure 3. Criteria maps

In the first stage, criteria weights are calculated with a pairwise matrix via AHP by specifying the importance of each criterion to another. The sum of the weights must be equal to 1 . Due to the high importance of geology and land use criteria, the weights are calculated as $\% 31$ and $\% 15$ with a 0.092 consistency ratio value which means the weights are consistent. The calculated weights are given in Table 3. 
Table 3. AHP weights

\begin{tabular}{lc}
\hline \multicolumn{1}{c}{ Criteria } & W \\
\hline Dist.Settlements & 0.04 \\
Sinkholes & 0.12 \\
Dist.Roads & 0.04 \\
Slope & 0.08 \\
Elevation & 0.08 \\
Faults & 0.10 \\
Landuse & 0.15 \\
Waterwells & 0.08 \\
Geology & 0.31 \\
\hline
\end{tabular}

\section{RESULTS}

The results indicate that $5,6 \%$ of the study area is assigned as susceptible according to the AHP calculation. As can be seen in Table 3, geology criterion have $31 \%$, land use $15 \%$ and sinkholes have $12 \%$ weights in total weight ranking. It is possible to say that approximately $60 \%$ of sinkhole susceptibility is defined by these classes. The total sinkhole susceptibility map is given in Figure 4.

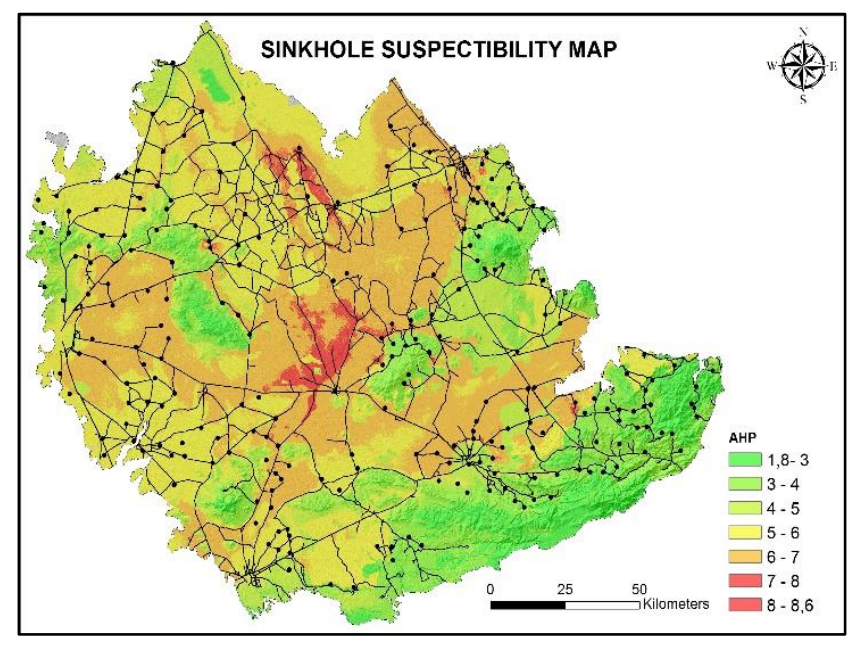

Figure 4. Suitability map

The effectiveness and reliability of the determined sinkhole susceptibility can be verified in several ways such as monitoring new sinkholes over next year and intersecting existing sinkholes with risk areas. When considering 128 existing sinkholes, 117 of them is located in $82 \%$ of risk area in susceptibility map. The new sinkholes then be located to test the reliability of this study. The detailed view of the susceptibility map and existing sinkhole intersection are given in Figure 5.

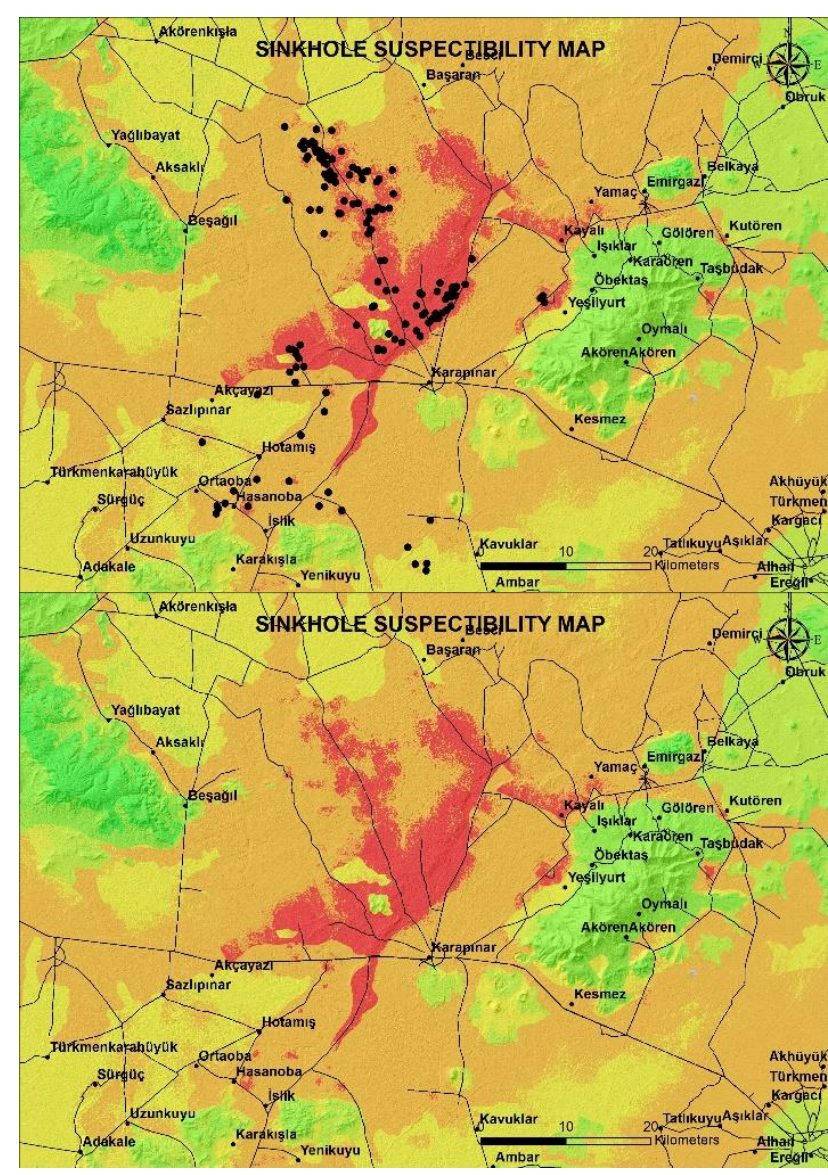

Figure 5. Susceptibility maps and intersections with existing sinkholes

\section{DISCUSSIONS}

Considering sinkhole formations trend, they are getting close to roads, agricultural lands and even urban areas. Beyond economic damage, urban area and roads mean, too many human life can be lost in sudden sinkhole formations. When considering all the projects and research notes on Karapınar, there two main reason can be listed for sinkholes. First reason is extreme groundwater usage for irrigation and crop selection which needs water above average. Another reason is the geologic formation and limestone structure of Karapinar. First of all, multidisciplinary projects must be realized to generate sinkhole susceptibility maps and predictions of new sinkholes accurately. The roads, urban areas and agricultural lands must be specified which are under sinkhole risk. Economic and human life lost must be considered. Another vital issue for Karapınar is irrigation projects. If groundwater usage will not limited and irrigation water is not supplied outside from Karapınar and basin, the sinkhole count will be increased rapidly.

\section{REFERENCES}

Arentze, T. A., Timmermans, H. J. P., 2000. ALBATROSS: A Learning-based Transportation Oriented Simulation System. EIRASS, Eindhoven University of Technology, The Netherlands. 
Chen, Y., Yua, J., Khan, S., 2010. Spatial sensitivity analysis of multi-criteria weights in GIS-based land suitability evaluation. Environmental Modelling \& Software 25, 1582-1591.

Galve, J.P., Castañeda, C., Gutiérrez, F., Herrera, G., 2015. Assessing sinkhole activity in the Ebro Valley mantled evaporite karst using advanced DInSAR. Geomorphology 229 (0), 30-44

Gutiérrez, F., Cooper, A.H., Johnson, K.S., 2008. Identification, prediction and mitigation of sinkhole hazards in evaporite karst areas. Environmental Geology 53, 1007-1022.

Miao, X., Qiu, X., Wu, S.-S., Luo, J., Gouzie, D.R., Xie, H., 2013. Developing efficient procedures for automated sinkhole extraction from Lidar DEMs. Photogramm. Eng. Remote Sens. 79 (6), 545-554.

Rahimi, M., Alexander, E.C., 2013. Locating Sinkholes in LiDAR Coverage of a Glacio-fluvial Karst, Winona County, MN

Saaty, T. L. (1977). A scaling method for priorities in hierarchical structures. Journal of Mathematical Psychology, 15, 234-281.

Saaty, T. L., 1980. The analytical hierarchy process. New York: Wiley.

Saaty, T. L., 1994. Fundamentals of Decision Making and Priority Theory With The Analytical Hierarchy Process, RWS Publ. Pittsburg, 69-84.

Saaty, T, L., Decision Making with Dependence and Feedback: The Analytic Network Process, 2nd edition, PRWS Publications, Pittsburgh PA, 2001.

Saaty, T.L., Vargas, L.G., 1991. Prediction, Projection and Forecasting. Kluwer Academic Publishers, Dordrecht, 251 pp.

Shaban, A., Darwich, T., 2011. The role of sinkholes in groundwater recharge in the high mountains of Lebanon. J. Environ. Hydrol. 19.

Taheri, K., Gutiérrez, F., Mohseni, H., Raeisi, E., Taheri, M., 2015. Sinkhole susceptibility mapping using the analytical hierarchy process (AHP) and magnitude-frequency relationships: a case study in Hamadan province, Iran. Geomorphology 234 (0), 64-79.

Waltham, T., Bell, F., Culshaw, M., 2005. Sinkholes and subsidence. Chichester, Springer 